\title{
Evaluating Drinking Water Treatment Methods in the Njala University and Neighboring Mokonde Communities in Southern Sierra Leone
}

\author{
Abdulai Barrie*, Abubakarr Swaray, Mariatu Barrie, Joe Beah \\ Environmental and Social Management Specialist, Research for Evidence-Based and Achievable Decisions, Freetown, Sierra Leone \\ (READ-SL) \\ Email: *abdulai.barrie@fulbrightmail.org
}

How to cite this paper: Barrie, A., Swaray, A., Barrie, M. and Beah, J. (2021) Evaluating Drinking Water Treatment Methods in the Njala University and Neighboring Mokonde Communities in Southern Sierra Leone. Natural Resources, 12, 257-270. https://doi.org/10.4236/nr.2021.128019

Received: July 7, 2021

Accepted: August 15, 2021

Published: August 18, 2021

Copyright () 2021 by author(s) and Scientific Research Publishing Inc. This work is licensed under the Creative Commons Attribution International License (CC BY 4.0).

http://creativecommons.org/licenses/by/4.0/

\begin{abstract}
Rural communities in sub-Saharan Africa (SSA) are always faced with the challenge of securing safe water for beneficial uses. Most communities lack a centralized water supply system and, thus, each residence utilizes the treatment method that they can afford. This study evaluated three treatment methods for drinking water in the Njala University and Mokonde communities in southern Sierra Leone. In the perceived natural treatment, residents in the Mokonde community believe that groundwater has been purified by the soil media and, hence, does not require further treatment. In the conventional treatment, the Njala University Water Works use sand filtration and chlorine disinfection to treat water from the Taia River. The third treatment method, first flush diversion, was introduced by Njala University researchers in 2014. We studied the populations of coliform bacteria and $E$. coli in untreated and treated water samples to determine if each of the treatment methods supported the beneficial use of drinking. This study concludes that the natural filtration does not remove pathogens in the well water. Even though the first flush and conventional treatments were efficient in reducing microbial populations in the water, the World Health Organization's 100\% removal guideline was not achieved most of the time. Therefore, all three treatment methods did not support the beneficial use of drinking. Further treatment was needed to render the water potable.
\end{abstract}

\section{Keywords}

Perceived Natural Treatment, Conventional Treatment, First Flush Diversion, 
Total Coliform, Fecal Coliform, E. coli, Beneficial Use

\section{Introduction}

A major challenge facing rural communities in sub-Saharan Africa (SSA) is to ensure sustainable supply of safe water for beneficial uses such as domestic use (drinking, bathing, food preparation, and cleaning), recreation, and irrigation. Residents fetch water from diverse sources including hand-dug wells, rivers, rainfall, springs, and streams [1] [2] [3]. In addition to these traditional sources, package drinking water, especially sachet water, has become a major supply source of drinking water in the region [4]. Each of these sources receives a different form of treatment. The two main treatment goals are to remove dirt and to disinfect the water.

In Sierra Leone, most rural communities do not have a centralized water supply system. Each household adopts treatment options that are customized to their needs and income level. Unfortunately, there are no regulatory standards that target those diverse treatment options to protect the health of the populations [5]. There is a need to evaluate drinking water treatment options and provide recommendations that may guide best practice thereby ensuring protection of public health in rural communities in Sierra Leone. The treatment options evaluated here include perceived natural treatment, first-flush diversion of rainwater from roof tops, and conventional water treatment.

A major treatment option in rural Sierra Leone is perceived natural treatment. Community members believe that groundwater is pure and, hence, does not require further treatment [6]. Unfortunately, groundwater is not protected from fecal and chemical contamination [7] because of pathogen transport from contiguous septic systems and the hydrogeological, geochemical, and physical characteristics of the Landscape [8]. A 2015 study in southern Sierra Leone asserted that up to $48 \%$ of annual rainfall end up as groundwater [2] potentially transporting fecal contamination from those contiguous pit latrines.

Rainwater harvesting simply involves the collection and storage of water from surfaces on which rain falls. Normally, water is collected from rooftops of buildings and stored in containers and rainwater tanks. Sierra Leone has two main seasons; the rainy season, which lasts from early May to late November, and the dry season, which lasts from late November to end of April. With an annual rainfall of about $2438 \mathrm{~mm}$, rainwater is a major water source in the study area [2].

The problem with rainwater is contamination from microbes and dust accumulated on rooftops during the dry season [9]. First-flush diversion is one of the cost-effective methods used to reduce contaminant loads in rainwater systems [10]. In first-flush diversion, the initial rainfall that washes the roof is diverted as wastewater before water is allowed into the storage tank. 
The literature does not provide a universal figure as to how much water should be diverted, or whether such diversion should be based on volume, depth, or rainfall intensity. The basic idea behind first-flush diverters is that the dirt in a stream of water coming off a roof is also an indication that the roof is becoming cleaner. Yaziz et al. (1989) estimated the volume of water diverted to render rainwater safe for consumption. They found that 5 liters of the first rainwater diverted allowed significant reduction in contamination [10]. Studies have suggested that factors such as the roofing type [11], roof catchment areas, and time [12] should also be considered in determining the first flush diversion. This study utilized the results of a 2014 first flush diversion project carried out in the Mokonde community, southern Sierra Leone [13].

In the conventional drinking water treatment, the raw water pump is immersed in a water source such as a river, lake, or well, which lifts water to a treatment center. At the treatment center, the water passes through slow filters comprising of graded layers of sand, gravel, and, in some cases, chemical adsorption layers. The filtered water is then disinfected with either a chemical disinfectant or energy from heat or ultraviolet light. The treated water is usually stored in a tank to await distribution by gravity flow to consumers. This study utilized the results of a 2017 research that evaluated the safety of water supplied from the Njala University Water Works, a conventional treatment system [1].

Coliform bacteria have several species that share common characteristics such as shape, habitat, or behavior. Fecal coliforms, a subset of total coliform bacteria, live in the intestines of people and animals. They are generally not harmful, but they indicate the possible presence of harmful bacteria, viruses, and protozoans that also live in human and animal digestive systems. Since it is expensive and time consuming to test for all pathogens in water samples, most programs test for fecal coliforms as an indicator of the presence of harmful microorganisms in the water [14]. The World Health Organization (WHO) recommends that fecal coliform in drinking water should be zero count per $100 \mathrm{~mL}$ of water sample [15].

Escherichia coli (abbreviated as E. coli) are bacteria found in the environment, foods, and intestines of people and animals. Most strains of E. coli can make people and animals sick by causing diarrhea, urinary tract infections, respiratory illness and pneumonia, and other illnesses [16]. The WHO recommends a zero count of E. coli in drinking water [15].

We evaluate three drinking water treatment methods in Njala University, Njala campus and neighboring Mokonde community, a community that provides diverse services to the majority of students and staff of the university. Two of the treatment methods (perceived natural and conventional treatments) are common practice while the third, first flush diversion, has been piloted by a group of researchers in the area [13]. The objective is to determine if these treatment methods support the beneficial use of drinking. Because bacterial contamination is the major water quality issue in the area [1], we used Coliform 
bacteria and $E$. coli to evaluate each treatment method. This study also forwarded options for improving those treatment methods that did not meet the WHO drinking requirement. The outcome of this study may benefit drinking water treatment in all rural communities across the nation.

\section{Materials and Methods}

\subsection{Description of the Study Area}

Njala University, Njala campus is located on the north side of adjacent Mokonde community in Kori Chiefdom, Moyamba District. Figure 1 shows a map of the study area.

The university gets its water supply from the Taia River on the west side of the campus, a well with hand pump (Jarkie Body), and one open hand-dug well at Florence Carew (a female hostel of the university). Mokonde gets its water supply primarily from wells and rainfall. Water from a neighboring stream is used mainly for laundry and bathing.

The Njala campus Water Works has the capacity to produce 25,000 gallons of water per day. The two campus wells (Jarnkie Body and Florence Carew) also

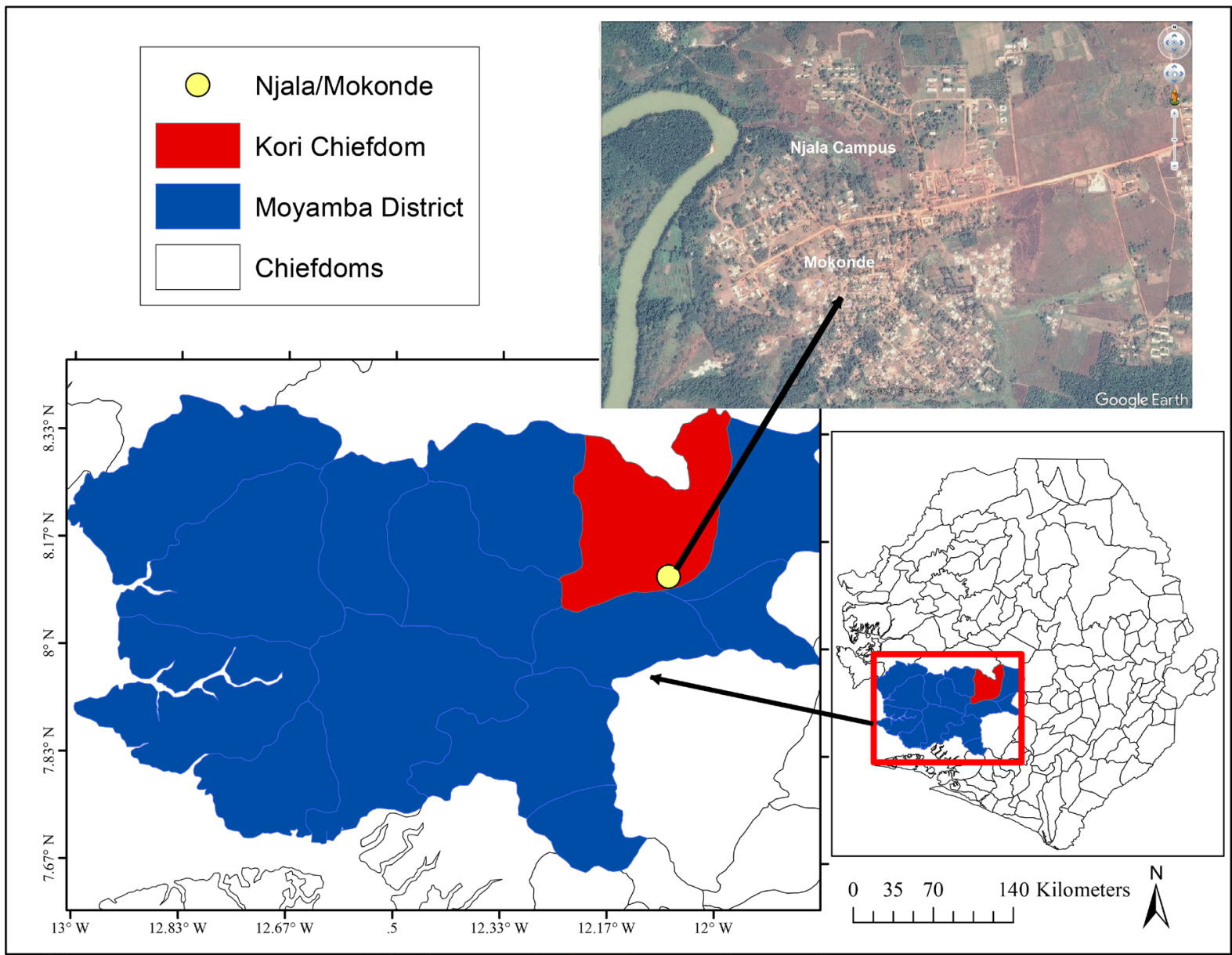

Figure 1. Map showing Sierra Leone (bottom right), Moyamba District, Kori Chiefdom (left), Njala campus, and Njala/Mokonde (top right). 
serve as a water source mainly for students. Sachet water is also a major source of drinking water on campus [4]. The Water Works is $200 \mathrm{~m}$ away from the intake point in Taia River; raw water is pumped through a 6-inch diameter pipe to the raw water tank (Tank-1). The raw water goes through sand filters of varying particle size at a filtration rate of about 1.74 gallons per minute (GPM). The filtered water flows through a 4 -inch diameter pipe into a disinfection tank where chlorine is manually added. The chlorine is diluted into predetermined concentrations and added to the filtered water. The treated water is stored in a finished water tank (Tank-2) from where the water is distributed to campus.

The estimated population of Mokonde is 2879 [2] with an average of 2 wells per every 20 households. The primary treatment method in the community is perceived natural treatment. A preliminary survey indicates that more than $85 \%$ of the population depend on perceived treatment. Perceived natural treatment in this context is defined by the widely held perception that the soil media purifies groundwater, and, as such, well water is consumed directly without any treatment.

\subsection{Sampling and Analysis}

This study used Coliform bacteria and E. coli to evaluate each of the treatment options in the two study communities. To evaluate the perceived natural treatment, we collected water samples from 2 wells located in Njala campus and 24 wells located in Mokonde. Figure 2 presents the locations of the sampled wells in the study area.

Plastic containers were used to draw water from the well and then a $500-\mathrm{mL}$ sample bottle used to grab sample from the container. Three replicate samples were collected from each container and all the samples were immediately transported to the lab for microbial analysis. A total of six samples were collected from each well, three samples in the dry season (April 2020) and three sets in the rainy season (June 20121).

The sample bottles were prepared according to Borsuah et al. (2014). Samples were collected in non-reactive, sterile bottles that were first washed with soap using tap water. The bottles were later rinsed with boiled water after which they were stored in household bleach with a dilution of $3 \%$, for 30 minutes to disinfect the bottles. The sample bottles were emptied, properly rinsed with boiled water, and then stored dried in the Lab.

The membrane filtration method with the HACH Field filtration Lab Kit was used to test rainwater samples for microbial contamination. The method is used to indicate the presence of coliform bacteria and E. coli. The M-coli Blue 24 broth has the ability to differentiate between total coliform and E Coli on the sterile petri dishes with absorbent pads.

The metal filter sand was first sterilized with a flame of fire for about 5 seconds; the tweezers were tipped in 70\% isopropyl alcohol and then disinfected with the fire flame for the same time. A filter was gently placed on the filter stand using the tweezers and the disposable filter cup assembled. A 10-mL disposable 


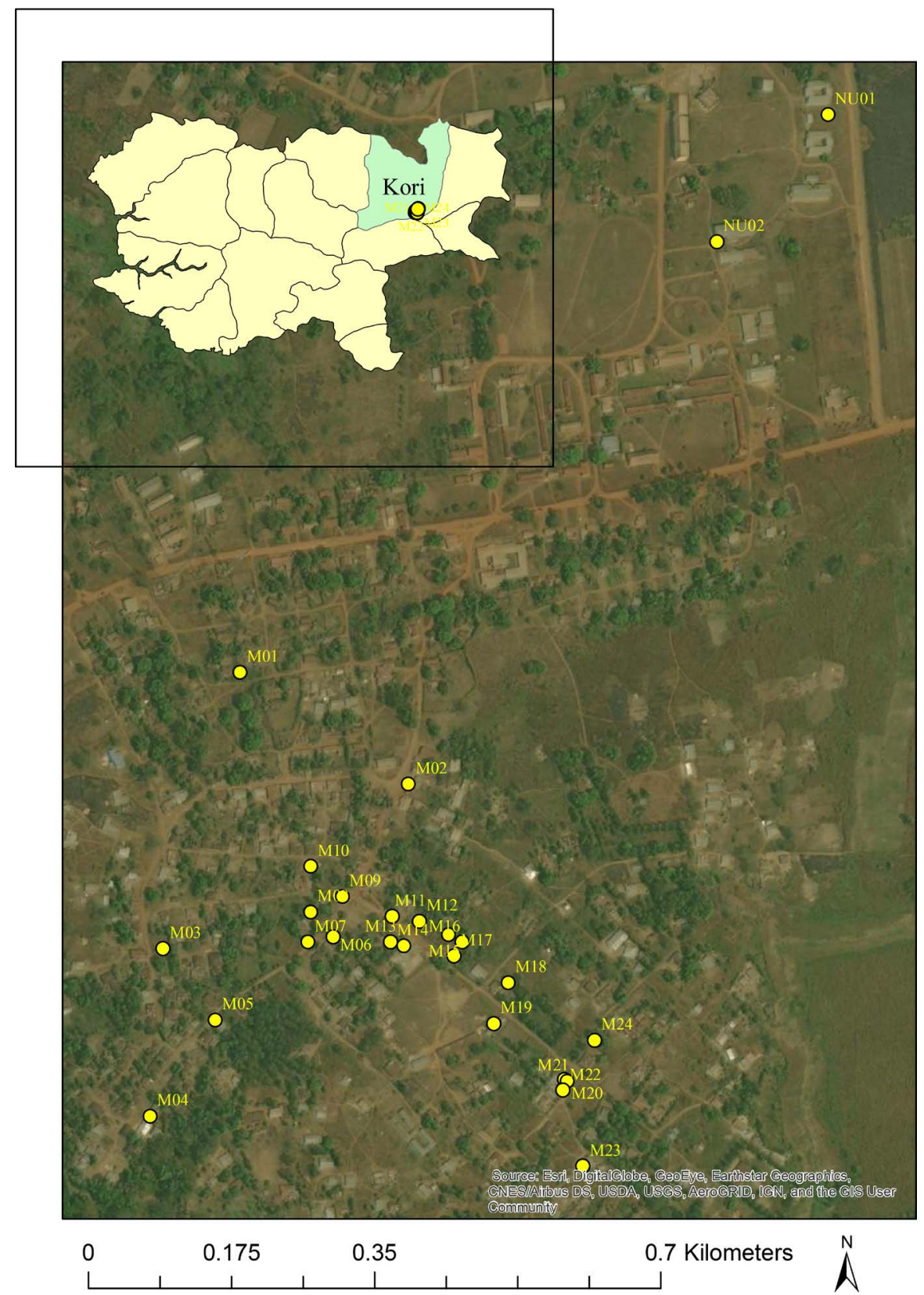

Figure 2. Map showing Kori Chiefdom in Moyamba District (top right) and locations of wells sampled (left).

pipette was used to pipette $10 \mathrm{~mL}$ of sample and poured in the cup. A $140-\mathrm{mL}$ syringe was used to strain the water sample through the $45-\mu \mathrm{m}$ filter paper. The $\mathrm{M}$-coli Blue 24 broth reagent was then poured in the petri dish and then the filter placed in the petri dish slowly. The prepared samples were placed in the Darwin chamber NQ series incubator and temperature regulated at $34^{\circ} \mathrm{C}$ to $36^{\circ} \mathrm{C} \pm 2^{\circ} \mathrm{C}$ for 24 hours after which Total Coliform and E. coli were counted.

To evaluate the first flush diversion, we utilized the results of Borsuah et al. (2014). The researchers harvested rainwater using an experimental setup with sample bottles of varying volumes and determined the populations of two mi- 
crobes, Total Coliform and E. coli, in each sample. Two years of data (2012-2014) were collected from two buildings at the UMC Primary School Mokonde. The two buildings were described "Mokonde Old (MO)" and "Mokonde New $(\mathrm{MN})$ ", by virtue of the age of the roofs on which the study was done.

Five bottles of different volumes were installed. At MN, there was one 1.5-L and four 0.5 -L sampling bottles, deployed in ascending order of volume. The MO setup had two 1.5-L sample bottles and three 0.5-L bottles, also in ascending order of volume. This setup was used to collect sample at the beginning and end of the rainy season and the arrangement was reversed in alternate rainy seasons. This study evaluated results of three sample sets collected on October 10, 2012; December 1, 2012, and May 1, 2013.

The clean and empty sample bottles were deployed before the start of each rain event. The setup allowed rainwater to fill the bottles one after the other until all the sampling bottles were filled. The sample bottles were connected using half-inch PVC pipes with $90^{\circ}$ elbows, tee points and threaded male adaptors. All threaded connections were wrapped with white Teflon tape to prevent leaks; the elbows were affixed with PVC gauge. The slope was tilted at 5\% following Yaziz et al. (1989).

To evaluate the conventional treatment method, we used the results of a 2017 water safety study conducted by Mansaray et al. (2017). The authors measured Fecal Coliform counts in river water before and after treatment at the university water treatment center. The authors collected water samples during the rainy and dry seasons. Plastic bottles were washed clean, boiled and labeled accordingly. Each sample bottle was rinsed thrice with the sample to be collected before the actual sample was collected and closed tightly with the cover. All samples were transported to the laboratory within 30 minutes of collection. Samples were stored in a cooler with ice in order to approximate the prevailing conditions under which they were collected.

Mansaray et al. (2017) used the Oxfam Delagua Water Testing Kit for the microbial analysis. The kit has petri dishes, absorbent pads, membrane filters, a vacuum pump and grease. In order to prevent any form of contamination, the equipment and all other accessories were sterilized. Each sample was gently shaken for a minute to make sure there was an even distribution of micro-organisms present. $50 \mathrm{~mL}$ of the water sample was measured using a standard sterilized measuring cylinder and gently poured into the filtration assembly. With the application of the vacuum pump, the water sample was allowed to flow through the membrane filter of pore size 0.45 microns. The membrane filter was incubated for 18 - 22 hours at $44^{\circ} \mathrm{C}$ in order to form suitable colonies of characteristic shape and color. Yellow Colonies were formed for the fecal coliform and other colors for the non-fecal coliform bacteria. The coliform bacteria were computed as counts per $100 \mathrm{ml}$ of water sample as follows: [Number of colony forming unit/Volume of water sample filtered $(50 \mathrm{~mL})] \times 100$. 


\section{Results and Discussion}

\subsection{Perceived Natural Treatment}

Figure 3 presents the microbial counts per $100 \mathrm{~mL}$ of sample from the 26 wells covered in this study. The bottom of the bar represents dry season numbers while the top of the bars represent rainy season counts.

The bacterial counts were higher in the rainy season probably because infiltration transported the microorganisms from septic systems into the wells [8]. Because all the wells had microbial counts that exceeded the WHO recommended value, this meant that the perceived natural treatment would not support the beneficial use of drinking. Further treatment was required to render the water potable.

The major issue appears to be lack of education about the quality of groundwater. Even though several studies have proven that groundwater can be contaminated from anthropogenic sources [17] [18] [19], members of the community still believe that groundwater is the safest water source and does not require further treatment. Additionally, the community does not have the resources to institute a centralized water treatment system. A possible solution could be the improvement and expansion of the Njala University water treatment and supply program to provide safe drinking water for both the university and the Mokonde community.

\subsection{First Flush Diversion}

Figure 4 presents the microbial counts per $100 \mathrm{~mL}$ of rainwater samples from

(a)

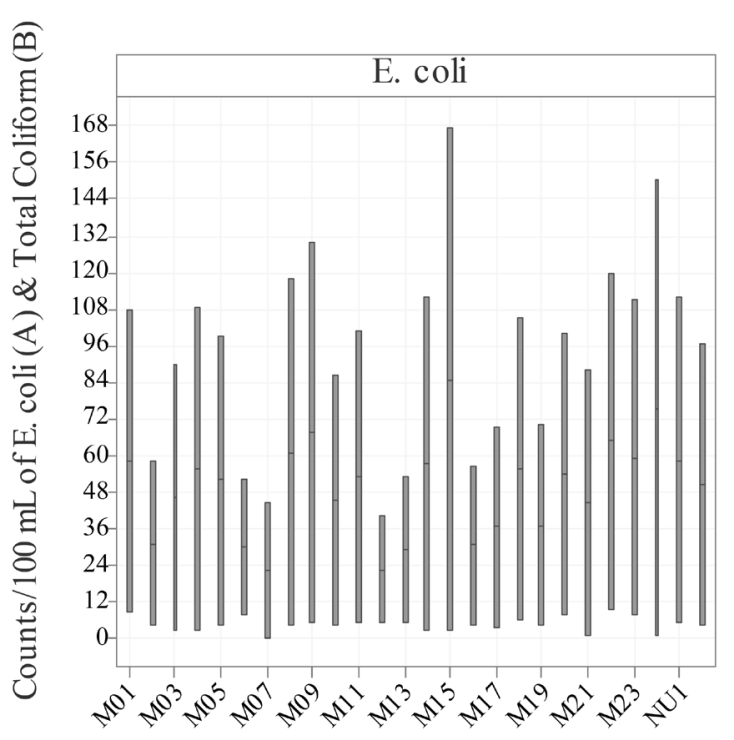

(b)

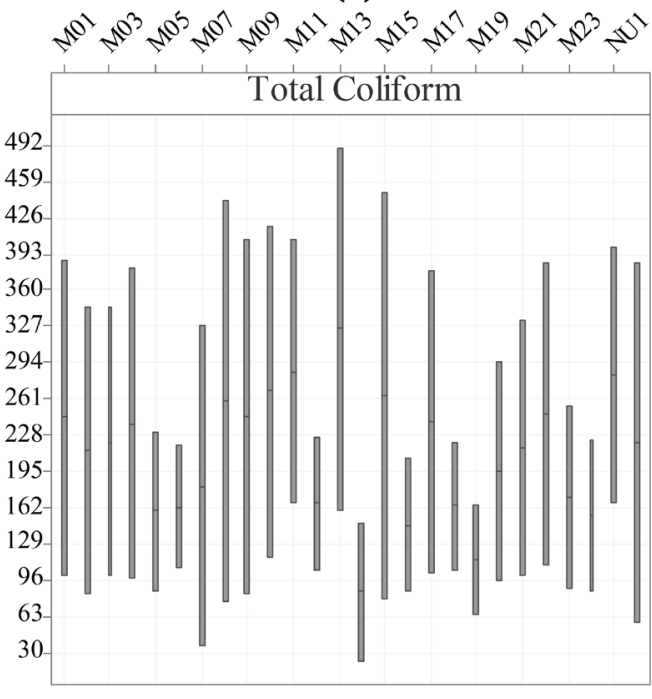

Well

Figure 3. E. coli (Panel (a)) \& Total Coliform (Panel (b)) counts/100mL sample from wells in Mokonde (M) and Njala Campus (NU). 


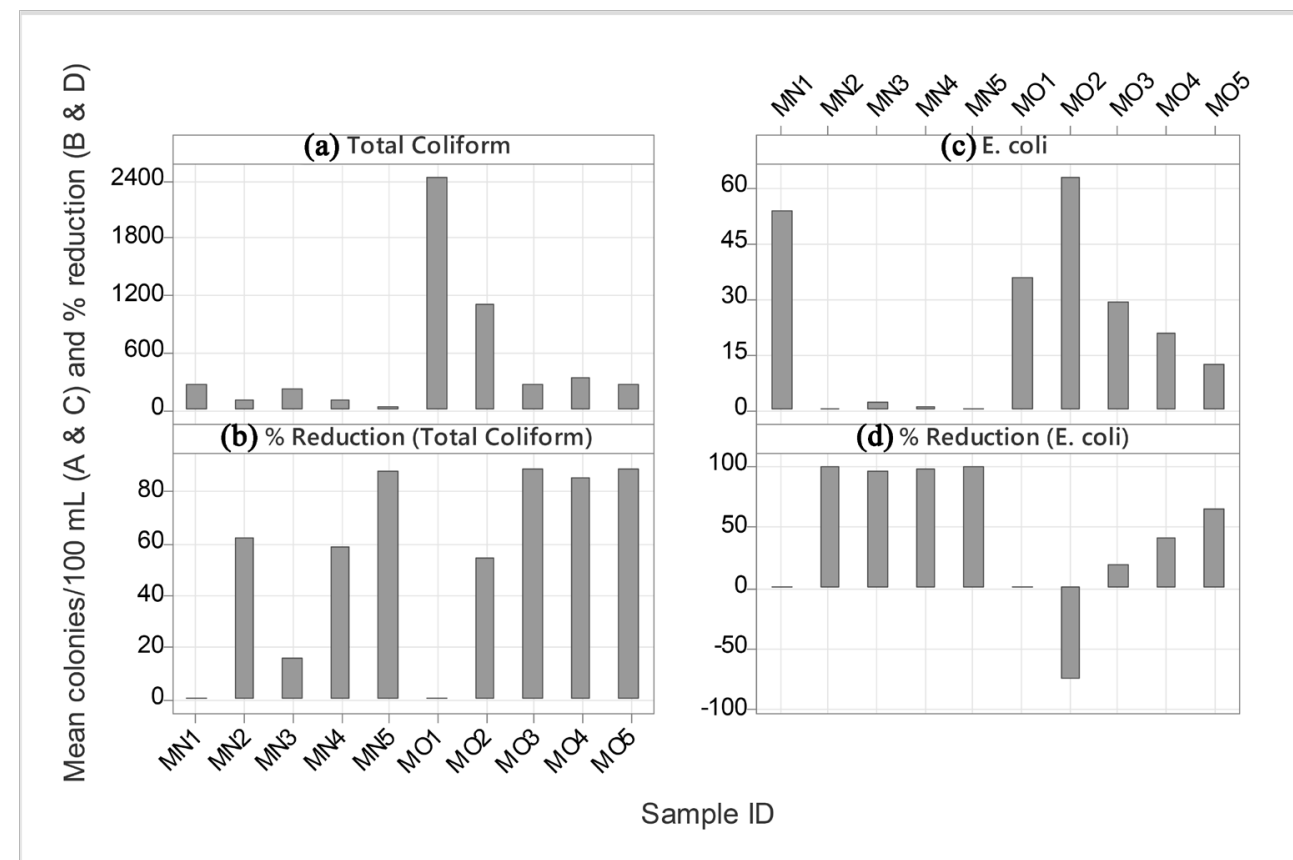

Figure 4. Total Coliform (Panel (a)), its \% reduction (Panel (b)), E. coli (Panel (c)) \& its \% reduction (Panel $(d))$ in the rainwater samples.

the rooftops of the study area. The expectation was that the first sample bottle (MO1 and MN1) would hold the highest number of microbial colonies because it receives the first rainwater that washes the rooftop when it has the most contamination; the number is expected to reduce as filling progresses because the rooftop is expected to be clean after several minutes of continuous rainfall. The percentage reduction was calculated on the basis of the microbial counts in the first sample bottle. For example, the percent reduction from the first to subsequent sample bottles at the older rooftop would be $((M O 1-M o i) / M O 1)^{*} 100$, where $\mathrm{i}=$ $2,3,4$, and 5 . Negative percentages indicate an increase in microbial counts.

For the newer rooftop (MN1 - MN5), the average coliform counts dropped from 267 in the $1^{\text {st }}$ sample bottle to 100 in the $2^{\text {nd }}$ sample bottle, a $62.5 \%$ reduction. More coliform bacteria were received in the $3^{\text {rd }}$ sample bottle $(225$ counts $/ 100 \mathrm{~mL})$ than the $2^{\text {nd }}$ sample bottle, which dropped the percent reduction to $15.75 \%$. The percent reduction increased to $59 \%$ in the $4^{\text {th }}$ sample bottle and $88.75 \%$ in the $5^{\text {th }}$ sample bottle. The E. coli results on the newer rooftop dropped significantly from the $1^{\text {st }}$ to the $2^{\text {nd }}$ sample bottle (100\% reduction) and, even though a slight increase took place between the $2^{\text {nd }}$ and the $3^{\text {rd }}$ sample bottles ( 0 to 2 counts $/ 100 \mathrm{~mL}$ ), there was a $100 \%$ reduction in the $5^{\text {th }}$ sample bottle.

The older roof had more microbial counts suggesting its tendency to provide a more thriving habitat for the microorganisms. The average number of Total Coliform colonies that needed to be removed was 2436 counts $/ 100 \mathrm{~mL}$. The reduction was at $55 \%$ in the $2^{\text {nd }}$ bottle and $90 \%$ reduction was achieved in the $5^{\text {th }}$ bottle. For E. coli, there was an increase in microbial counts from the first to the second sample bottle (from 36 to 63 counts $/ 100 \mathrm{~mL}$ ). The $E$. coli counts were re- 
duced by $66 \%$ between the $1^{\text {st }}$ and $5^{\text {th }}$ sample bottles.

Based on the first flush experiment carried out by Borsuah et al. (2014), the minimum treatment efficiency of diverting the firs $3500-4500 \mathrm{~mL}$ of rainwater from rooftops in the study area is $66 \%$. Thus, the treatment method is effective at removing microorganisms from rainwater. However, further treatment is needed to achieve a $100 \%$ reduction and render the rainwater potable in the community.

First flush diversion provides the opportunity to significantly reduce the disinfection demand and hence the cost of securing chemicals such as chlorine. Borsuah et al. (2014) recommended the coupling of biosand filters with first flush diversion to achieve maximum treatment efficacy with no cost to the household. Other studies have also suggested that first flush diversion alone may not be enough to completely remove contaminants from diverse sources such as sediments, bird droppings, spiders, insects, mosquito eggs and debris [20]. Other reasons why the first flush diversion needs to be coupled with other forms of treatment include its lack of residual disinfection and the possibility of wasting large volumes of diverted water [21].

\subsection{Conventional Treatment Option}

Figure 5 presents the fecal coliform counts in untreated and treaded water at Njala Campus. The lower ends of the bars in the left panel represent the dry season counts while the upper ends represent the rainy season counts. The left panel represents Fecal Coliform counts per $100 \mathrm{~mL}$ of sample while the right panel represents the percent reductions in Fecal Coliform populations after

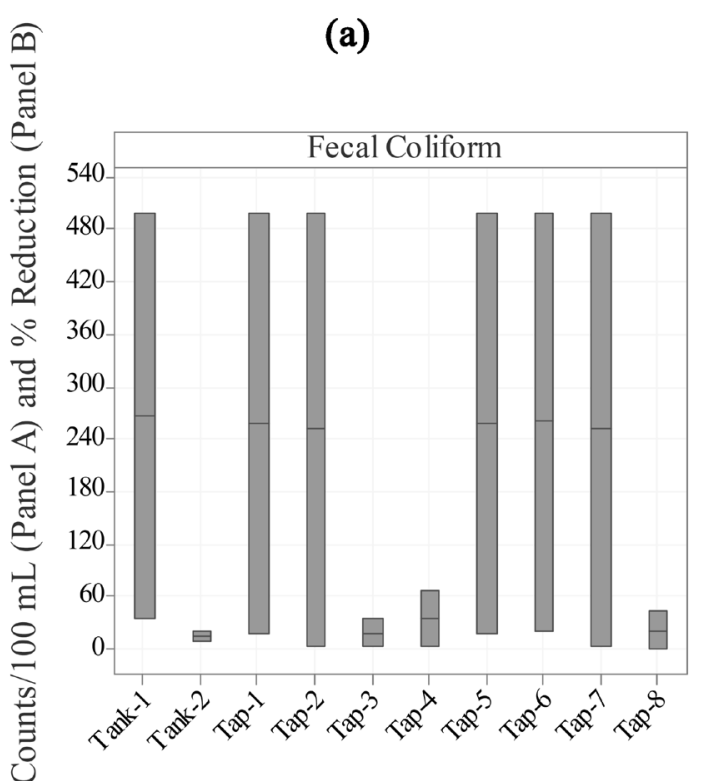

(b)

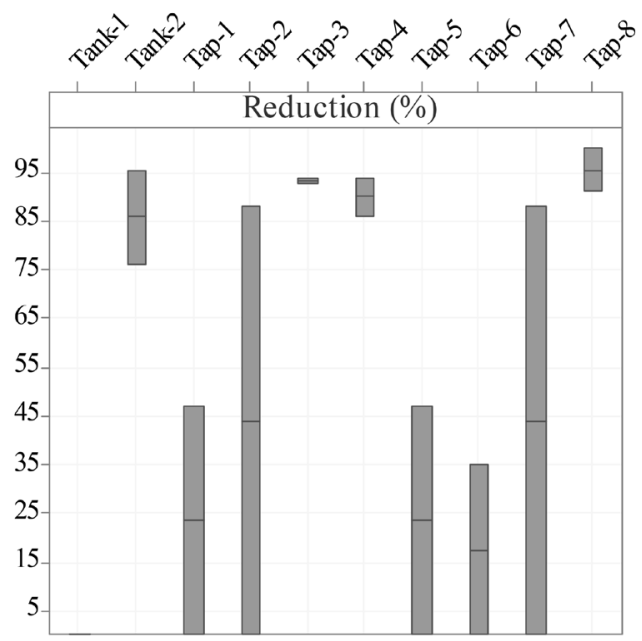

Sample location

Figure 5. Fecal Coliform counts/100mL of water samples (Panel (a)) and the \% reductions (Panel (b)). 
treatment. The percent reduction is given as $((T 1-T i) / T 1){ }^{*} 100$; where $T 1$ is Tank-1 and Ti represents Tank-2 and Tap-1 to Tap-8.

In the dry season, there was a $76.5 \%$ reduction in Fecal Coliform count when water was moved from the untreated water tank (Tank 1) through the filtration and disinfection setup to the treated water tank (Tank 2). The rainy season reduction was $95.6 \%$. At Tap-1, the dry season reduction was $47.1 \%$; in the rainy season, however, the bacterial count at this tap grew to the original amount in the raw water tank, bringing it to $0.0 \%$ reduction. Similar results as those in tap 1 were recorded at Tap-2 (88.2\% reduction in the dry season and $0.0 \%$ reduction in the rainy season), Tap- 5 ( $47.1 \%$ reduction in the dry season and $0.0 \%$ reduction in the rainy season), Tap-6 (35.3\% reduction in the dry season and $0.0 \%$ reduction in the rainy season), and Tap-7 (88.2\% reduction in the dry season and $0.0 \%$ reduction in the rainy season). Tap- 8 was the only supply point where a zero bacterial count was observed in the dry season and a $91.4 \%$ reduction in the rainy season. These results suggest that Tap- 8 is less susceptible to recontamination compared to the other supply points.

Because Fecal Coliform bacteria were still in the treated water, it meant that the chlorine demand was higher than the amount added for disinfection, which may have resulted in zero residual disinfection. The initial population either remained the same or increased significantly in the water samples collected at the various taps on campus. Mansaray et al. (2017) asserted that reintroduction of pathogens along the supply network was a strong possibility. Even though conventional water treatment is a universally acceptable treatment method, the Njala University treatment setup did not support the beneficial use of drinking at this time. There was the need to improve on the treatment setup at the Water Works [1].

\section{Conclusions}

The goal of water treatment is to render water safe for direct human consumption. Different treatment methods have been advanced to remove physical, biological, and chemical contaminants. These methods must satisfy regulatory or recommended standards that have been developed by agencies and organizations [15] [22] [23]. This study evaluated three treatment methods for drinking water in the Njala University and Mokonde communities in southern Sierra Leone namely, first flush diversion, perceived natural treatment, and the conventional method. Two of the treatment methods, perceived natural and conventional treatments, are common in the area. In 2012, a rainwater treatment method called first flush diversion was introduced by Borsuah et al., to minimize the burden of treatment costs.

In the perceived natural treatment, residents in the Mokonde community believe that groundwater has been purified by the soil media and, hence, do not require further treatment. Most of the population drink water from wells. In the conventional treatment, the Njala University Water Works pumps water from 
neighboring Taia River, pass it through sand filtration, and then apply chlorine to disinfect the water before supplying to campus. In the first flush diversion method, the initial rainwater falling on rooftops is diverted until the water is clean enough to be harvested and stored into storage tanks.

This study used coliform bacteria and E. coli to determine if each of the treatment methods supports the beneficial use of drinking. Our evaluation concludes that none of the three methods support the beneficial use of drinking because there were microbes present in the water that was considered as treated, which violated the WHO recommended guideline.

Even though the first flush diversion and conventional treatments proved efficient in terms of the percent reduction in microbial populations, further treatment was required to render the water potable. Borsuah et al. (2014) recommended further treatment of harvested rainwater with the use of a biosand filtration system while Mansaray et al. (2017) recommended improvement in the setup at Njala University to bring the Chlorine demand to zero and increase residual disinfection to recommended guidelines.

Acknowledgments: Some of the data used in this study were provided by Borsuah et al. (2014, and Mansaray et al. (2017). The Njala University facilities were used to carry out this research. Funding for the well sampling was provided by the Research for Evidence-based and Achievable Decisions (READ-SL).

\section{Acknowledgements}

Collaborators that made the First Flush Diversion project possible include Jessica J. Lay, Josephus F. Borsuah, Bashiru M Koroma, and Alhaji Brima Gogra.

\section{Conflicts of Interest}

The authors declare no conflicts of interest regarding the publication of this paper.

\section{References}

[1] Mansaray, A.S., Borsuah, J.F., Gogra, A.B., Fofanah, B.B. and Koroma, B.M. (2017) The Safety of Water Supplied at Njala University, Njala Campus. Scientific Research, 8, 81-93. https://doi.org/10.4236/nr.2017.82006

[2] Mansaray, A.S., Gogra, A.B. and Massaquoi, A.S. (2015) The Recharge Potential of Groundwater in the Mokonde Community in Southern Sierra Leone. Natural Resources, 6, 543-552. https://doi.org/10.4236/nr.2015.611052

[3] MacDonald, A.M. and Davies, J. (2000) A Brief Review of Groundwater for Rural Water Supply in Sub-Saharan Africa. British Geological Survey, London.

[4] Mansaray, A.S., Kaisam, J.P., Bockarie, A.S. and Sam, H. (2016) Consumer Preferences for Water Supply at Njala University, Njala Campus in Southern Sierra Leone. Natural Resources, 7, 138-145. https://doi.org/10.4236/nr.2016.73014

[5] Mansaray, A., Aamodt, J. and Koroma, B.M. (2018) Water Pollution Laws in Sierra Leone-A Review with Examples from the UK and USA. Natural Resources, 9, 361-388. https://doi.org/10.4236/nr.2018.911023

[6] Lewis, L. (2021) Rueal and Urban Water Issues in Africa. The Water Project. 
https://thewaterproject.org/water-crisis/water-in-crisis-rural-urban-africa

[7] Ibemenuga, K.N. and Avoaja, D.A. (2014) Assessment of Groundwater Quality in Wells within the Bombali District, Sierra Leone. Animal Research International, 1, 1905-1916.

[8] Ferrer, N., Folch, A., Masó, G., Sanchez, S. and Sanchez-Vila, X. (2020) What Are the Main Factors Influencing the Presence of Faecal Bacteria Pollution in Groundwater Systems in Developing Countries? Journal of Contaminant Hydrology, 228, 103556-103567. https://doi.org/10.1016/j.jconhyd.2019.103556

[9] Lye, D.J. (2009) Rooftop Runoff as a Source of Contamination: A Review. Science of the Total Environment, 407, 5429-5434.

https://doi.org/10.1016/j.scitotenv.2009.07.011

[10] Yaziz, M.I., Gunting, H., Sapari, N. and Ghazali, A.W. (1989) Variations in Rainwater Quality from Roof Catchments. Water Research, 23, 761-765. https://doi.org/10.1016/0043-1354(89)90211-X

[11] Mendez, C.B., Klenzendorf, J.B., Afshar, B.R., Simmons, M.T., Barrett, M.E., Kinney, K.A. and Kirisits, M.J. (2011) The Effect of Roofing Material on the Quality of Harvested Rainwater. Water Research, 45, 2049-2059.

https://doi.org/10.1016/j.watres.2010.12.015

[12] Amin, M.T., Kim, T., Amin, M.N. and Han, M.Y. (2013) Effects of Catchment, First-Flush, Storage Conditions, and Time on Microbial Quality in Rainwater Harvesting Systems. Water Environment Research, 85, 2317-2329.

https://doi.org/10.2175/106143013X13706200598433

[13] Borsuah, J., Lay, J., Mansaray, A.S. and Koroma, B.M. (2014) Ensuring Beneficial Uses of Harvested Rainwater in Rural Sierra Leone. Njala University Dissertation Archives, Njala Campus.

[14] USEPA (2012, March 6) Fecal Bacteria-What Are Fecal Bacteria and Why Are They Important? United States Environmental Protection Agency, Washington DC. https://archive.epa.gov/water/archive/web/html/vms511.html

[15] WHO (2017) Guidelines for Drinking-Water Quality: Fourth Edition Incorporating the First Addendum. The World Health Organization, Geneva.

[16] CDC (2021, March 11) Escherichia coli (E. coli). Centers for Disease Control and Prevention, Atlanta. https://www.cdc.gov/ecoli/index.html

[17] Tufenkji, N. and Emelko, M. (2011) Fate and Transport of Microbial Contaminants in Groundwater. In: Nriagu, J.O., Ed., Encyclopedia of Environmental Health, Elsevier, Amsterdam, 715-726. https://doi.org/10.1016/B978-0-444-52272-6.00040-4 https://sciencedirect.com/science/article/pii/b9780444522726000404

[18] Scandura, J.E. and Sobsey, M.D. (1997) Viral and Bacterial Contamination of Groundwater from On-Site Sewage Treatment Systems. Water Science and Technology, 35, 141-146. https://doi.org/10.2166/wst.1997.0724

[19] Feighery, J., Mailloux, B.J., Ferguson, A., Ahmed, K.M., Geen, A.V. and Culligan, P.J. (2013) Transport of E. coli in Aquifer Sediments of Bangladesh: Implications for Widespread Microbial Contamination of Groundwater. Water Resources Research, 49, 3897-3911. https://doi.org/10.1002/wrcr.20289

[20] Zahir, M., Naz, A., Ahmed, T. and Ahmad, M. (2019) Estimation of First-Flush Diverter Phenomena through Volume Based Grab Sampling of Rainwater. Sindh University Research Journal, 50, 335-340.

[21] Doyle, K.C. and Shanahan, P. (2012) Effect of First Flush on Storage-ReliabilityYield of Rainwater Harvesting. Journal of Water Sanitation and Hygiene for Devel- 
opment, 2, 1-9. https://doi.org/10.2166/washdev.2012.055

[22] USEPA (2017, September 1) Drinking Water Requirements for States and Public Water Systems. https://www.epa.gov/dwreginfo/drinking-water-regulations

[23] Gara, T., et al. (2018) Health Safety of Drinking Water Supplied in Africa: A Closer Look Using Applicable Water-Quality Standards as a Measure. Exposure and Health, 10, 1-12. 